\title{
Patient preferences in the treatment of diabetic retinopathy
}

\author{
This article was published in the following Dove Press journal: \\ Patient Preference and Adherence \\ 23 May 20II \\ Number of times this article has been viewed
}

\author{
Barbara Wirostko' \\ Kathleen Beusterien ${ }^{2}$ \\ Jessica Grinspan² \\ Thomas Ciulla ${ }^{3}$ \\ John Gonder ${ }^{4}$ \\ Alexandra Barsdorf ${ }^{\prime}$ \\ Andreas Pleil ${ }^{5}$ \\ 'Pfizer, New York, NY, USA; ${ }^{2}$ Oxford \\ Outcomes, Bethesda, MD, USA; \\ ${ }^{3}$ Midwest Eye Institute, Indianapolis, \\ IN, USA; ${ }^{4}$ Ivey Eye Institute, London, \\ Ontario, Canada; ${ }^{5}$ Pfizer Inc, San \\ Diego, CA, USA
}

Objective: Accounting for patient preferences may be especially important in diabetes mellitus, given the challenge in identifying factors associated with treatment adherence. Although preference studies have been performed in diabetes, none have examined treatments used in diabetic retinopathy (DR). The objective of this study was to elicit patient preferences for attributes associated with antivascular endothelial growth factor, focal and panretinal laser, and steroid therapy used in DR management.

Methods: A cross-sectional conjoint survey was administered to DR patients at three Canadian eye centers. The survey involved making tradeoffs among 11 DR treatment attributes, including the chance of improving vision and risks of adverse events over a 1-year treatment period. Attribute utilities were summed for each product profile to determine the most preferred treatment.

Results: Based on the results from 161 patients, attributes affecting visual functioning, including improving visual acuity and reducing adverse events (eg, chance of cataracts), were more important than those not directly affecting vision (eg, administration). Overall, $52 \%, 20 \%$, $17 \%$, and $11 \%$ preferred the product profiles matching to the antivascular endothelial growth factor, steroid, focal laser, and panretinal laser therapies. Preferences did not vary substantially by previous treatment experience, age, or type of DR (macular edema, proliferative DR, both or neither), with the exception that more macular edema only patients preferred focal laser over steroid treatment (19\% versus $14 \%$, respectively).

Conclusions: When considering the potential effects of treatment over a 1-year period, treatment preferences in DR are most influenced by those that may positively or negatively affect visual functioning.

Keywords: diabetes, retinopathy, patient preference, ophthalmology, conjoint analysis

\section{Introduction}

An underlying theme of the American Diabetes Association treatment guidelines is that providers should elicit and incorporate patient preferences in treatment decisions. ${ }^{1}$ Individualizing patient care and accounting for patient preferences may be especially important in diabetes mellitus, given the challenge in identifying key factors associated with adherence to recommended chronic care and more favorable clinical outcomes over the long term. ${ }^{2}$ In addition, as Brown et al have observed, preferences among older diabetes patients for intensity of treatment regimen vary widely and are not closely associated with clinical status, eg, life expectancy and amount of functional decline. ${ }^{1}$ Although adherence to recommended care can markedly reduce complication rates in diabetes mellitus, it has been estimated that $45 \%$ of persons diagnosed with diabetes mellitus in the US actually adhere to such care. ${ }^{3}$ A better understanding of
Correspondence: Jessica Grinspan 7315 Wisconsin Avenue, Suite $250 \mathrm{~W}$, Bethesda, MD 208I4, USA

Tel +l 2404820034, ext 23

Fax +I 2404820043

Email jessica.grinspan@

oxfordoutcomes.com 
patient preferences with respect to treatment may help to inform adherence rates, as suggested by previous studies in diabetes. ${ }^{4,5}$

Thus far, treatment preferences in diabetes have focused predominantly on treatment for glucose control and perceptions regarding treatment side effects. ${ }^{1,6,7}$ For example, Matza et al showed that side effects, such as weight gain or gastrointestinal adverse events, may impact patient preferences in type 2 diabetes. ${ }^{6}$ Consistent with previous findings that increasing the complexity of glucose therapies is associated with lower quality-of-life scores, Huang et al found that preferences for various glucose control regimens vary substantially and may significantly impact the cost-effectiveness of intensive glucose control among older patients with new-onset diabetes. ${ }^{7}$

Although treatment preference studies have been performed focusing on glucose control, they are lacking for treatments that may be considered for patients with diabetic retinopathy. Diabetic retinopathy (DR), a common ophthalmic complication of diabetes, occurs in over $50 \%$ of diabetic patients. The manifestations of DR, diabetic macular edema, and proliferative diabetic retinopathy, can lead to vision loss, as well as legal blindness. ${ }^{8-10}$ A recent projection study, using data from the National Health Interview Survey and the US Consensus Bureau, estimated that the prevalence of DR among diabetes patients aged 40 years and older will increase threefold, reaching 16 million, by $2050 .{ }^{11}$ In Canada, diabetes and DR have become a major public health problem, with nearly $5 \%$ of the population having diabetes, and 400 of these patients developing blindness every year from their disease. $^{12}$

Current treatment options for DR include laser photocoagulation, intravitreal steroid therapy, and, more recently, antiangiogenic intravitreal injections. Laser therapies, focal and panretinal argon photocoagulation laser, are the mainstay of treatment but often do not lead to marked visual improvement. ${ }^{13-18}$ They also risk damaging the neurosensory retina, depending on the location and intensity of the laser application and through possible laser scar expansion. ${ }^{19,20}$ Similarly long-term use of repeated intravitreal steroids to treat DR-related vision loss is limited due to the associated risk of elevated intraocular pressure and cataract formation. ${ }^{14}$ Recently, antiangiogenic therapies that target vascular endothelial growth factor (VEGF) have been promising in treating DR, especially diabetic macular edema, and are being considered as a viable alternative and/or addition to laser and steroid therapies. ${ }^{16,18,21}$ However, because these anti-VEGF drugs have a relatively short half-life, they require frequent intravitreal injections. They may also carry an increased risk of cardiovascular events, such as heart attack and stroke, because of the role anti-VEGF plays systemically. ${ }^{16,21,22}$

Given that current DR treatments have advantages or disadvantages relative to each other, it would be useful to understand patient preferences associated with the different treatmentrelated features and clinical outcomes. Conjoint analysis, a methodology widely used in market research as well as in medical research studies, involves having respondents make tradeoffs among these features (attributes), such as mode of administration and risk of adverse events. ${ }^{23-25}$ The resulting data, or utilities, enable the assessment of the relative importance of each treatment attribute; specifically, they show the influence that each attribute has on overall treatment preferences. In the context of eye disease, the conjoint approach has been used to assess which factors in the management and treatment of glaucoma were of most importance to patients. ${ }^{26}$

The goal of the present study was to use conjoint analysis to elicit preferences for attributes associated with DR treatments. Specifically, the survey aimed to assess the tradeoffs that DR patients in Canada are willing to make among attributes associated with anti-VEGF, steroid, focal laser, and panretinal laser treatment. Although steroids and anti-VEGF treatment are currently offlabel treatment for diabetic macular edema, and panretinal laser is only used for proliferative diabetic retinopathy, all four treatments that may be used at some point for the diabetes patient with DR were included in this assessment for comprehensiveness.

\section{Research design and methods}

A total of 171 study participants were recruited from three Canadian clinical eye care centers for this cross-sectional study. The study followed the tenets of the Declaration of Helsinki, and the study protocol was approved by each site-specific Institutional Review Board. All participants had a medical diagnosis of DR, and all stages of the disease were represented, including patients who had developed proliferative diabetic retinopathy, diabetic macular edema, both proliferative diabetic retinopathy and diabetic macular edema, and those with earlier-stage DR who had neither proliferative diabetic retinopathy nor diabetic macular edema. All participants were at least 18 years of age, provided informed consent, and were compensated $\$ 50.00$ for participation. Participants completed the conjoint survey via wide-screen computer monitors at the clinical sites. The survey was self-administered, and participants moved through the survey at their own pace, although 
a research assistant was available at each site to answer questions as needed.

\section{Survey design}

The 11 treatment attributes assessed in the survey were selected based on a literature review and consultation with three DR specialists. These attributes included mode of administration, required number of office visits, treatmentrelated pain, the chance of improving central vision, and the risk of adverse events, such as cataracts, glaucoma, and cardiovascular events. The descriptions of these attributes were based on a time horizon of one year after beginning treatment. Based on the literature and expert input, base case estimates were identified for the attributes for each of the four target treatments, ie, anti-VEGF, steroid, focal laser, and panretinal laser treatment ${ }^{17,27-33}$ (Table 1). It should be noted that we did not include "cost of treatment" as an attribute because this is not an important driver or barrier to treatment in Canada.

From the clinical averages and ranges observed in our preliminary research, each attribute was described using 2-3 levels that represented the full range of possibilities across the four DR treatments. These levels were not always the same estimates as in the base case scenario, but since the

Table I Base case estimates for diabetic retinopathy treatments

\begin{tabular}{|c|c|c|c|c|}
\hline Attribute & Selective VEGF inhibitor & Focal laser & Panretinal laser & Steroid \\
\hline $\begin{array}{l}\text { Number of physician visits } \\
\text { to receive treatment over } \\
\text { a one-year period }\end{array}$ & 9 visits & 2 visits & 6 visits & 2 visits \\
\hline $\begin{array}{l}\text { Administration of eye } \\
\text { treatment }\end{array}$ & $\begin{array}{l}\text { One injection of } \\
\text { medicine into eye }\end{array}$ & $\begin{array}{l}\text { Laser procedure, in } \\
\text { which } 40-60 \text { spots are } \\
\text { placed on a small area } \\
\text { of the central retina }\end{array}$ & $\begin{array}{l}\text { Laser procedure, in } \\
\text { which approximately } \\
500 \text { spots are placed } \\
\text { across the retina }\end{array}$ & $\begin{array}{l}\text { One injection of } \\
\text { medicine into eye }\end{array}$ \\
\hline Treatment-related pain & $\begin{array}{l}\text { Mild pain at the time } \\
\text { of treatment }\end{array}$ & $\begin{array}{l}\text { Mild pain at the time } \\
\text { of treatment }\end{array}$ & $\begin{array}{l}\text { Moderate pain at the time of } \\
\text { treatment, and some pain after } \\
\text { treatment lasting for a day }\end{array}$ & $\begin{array}{l}\text { Mild pain at the } \\
\text { time of treatment }\end{array}$ \\
\hline $\begin{array}{l}\text { Benefit observed from } \\
\text { subsequent treatments }\end{array}$ & $\begin{array}{l}\text { After treatment wears } \\
\text { off, same benefit is } \\
\text { observed with each } \\
\text { subsequent treatment }\end{array}$ & $\begin{array}{l}\text { After treatment wears } \\
\text { off, treatment benefit } \\
\text { decreases with each } \\
\text { subsequent treatment }\end{array}$ & $\begin{array}{l}\text { After treatment wears off, } \\
\text { treatment benefit decreases } \\
\text { with each subsequent } \\
\text { treatment }\end{array}$ & $\begin{array}{l}\text { After treatment wears } \\
\text { off, treatment benefit } \\
\text { decreases with each } \\
\text { subsequent treatment }\end{array}$ \\
\hline $\begin{array}{l}\% \text { chance of improving central } \\
\text { vision, in which you can } \\
\text { read two more lines of letters } \\
\text { on a vision chart }\end{array}$ & $30 \%$ & $20 \%$ & $33 \%$ & $40 \%$ \\
\hline $\begin{array}{l}\% \text { chance of having blurry } \\
\text { or blank patches in central } \\
\text { field of vision }\end{array}$ & $0 \%$ & $20 \%$ & $0 \%$ & $0 \%$ \\
\hline $\begin{array}{l}\% \text { chance of having blurry or } \\
\text { blank patches in your side vision, } \\
\text { which may result in difficulty } \\
\text { noticing objects off to the side } \\
\text { and seeing in dim light }\end{array}$ & $0 \%$ & $0 \%$ & $33 \%$ & $0 \%$ \\
\hline $\begin{array}{l}\text { \% chance of needing treatment } \\
\text { daily drops for glaucoma, which } \\
\text { is increased eye pressure }\end{array}$ & $0 \%$ & $0 \%$ & $0 \%$ & $35 \%$ \\
\hline $\begin{array}{l}\% \text { chance of needing surgery } \\
\text { for glaucoma (increased eye } \\
\text { pressure) in an operating room }\end{array}$ & $0 \%$ & $0 \%$ & $0 \%$ & $2 \%$ \\
\hline $\begin{array}{l}\% \text { chance of having misty vision } \\
\text { and/or glare from lights because } \\
\text { of cataract formation }\end{array}$ & $0 \%$ & $0 \%$ & $0 \%$ & $40 \%$ \\
\hline $\begin{array}{l}\% \text { chance of having heart } \\
\text { attack or stroke which } \\
\text { does not result in death }\end{array}$ & $1 \%$ & $0 \%$ & $0 \%$ & $0 \%$ \\
\hline
\end{tabular}

Note: almprovement in central vision after repeated treatments; ${ }^{a}$ number of visits specifically to receive diabetic retinopathy treatment, not routine follow-ups or monitoring for side effects.

Abbreviation: VEGF, vascular endothelial growth factor. 
base case estimates fell within the range of level values, they could be evaluated through interpolation. The levels were described using lay terminology, and the risks of adverse events were presented as “\% chance". In addition, props were used to further illustrate some of the attributes. The survey was pilot-tested in a sample of five DR patients to ensure that the language and questions were clear and easy to understand. No significant changes were required.

The survey had four sections. In the first section, patients were asked to rate the desirability of each attribute level on a seven-point scale from "very bad" to "very good". In section two, the importance of the most favorable level versus the least favorable level was rated from "not important" to "extremely important". Third, participants completed a series of pair-wise comparisons; each question presented two treatment profiles with three attribute levels, and participants indicated which profile they preferred on a seven-point scale from "strongly prefer A" to "strongly prefer B". This section was adaptive, ie, the responses to each paired comparison are used to update each respondent's utilities, and to select the next pairwise comparison shown. ${ }^{24}$ This approach to conjoint analysis is called adaptive conjoint analysis. ${ }^{24,34}$ In the fourth section, respondents provided information on demographics and treatment experience.

\section{Analysis}

Univariate analyses were performed using SAS software (version 9.1; to characterize demographic and clinical characteristics. Responses to previous treatment experience were used to identify four subgroups, ie, experience with laser, experience with injection, experience with both laser and injection, and treatment-naïve. Utilities were generated for every level of each attribute. This was an iterative process in which the desirability ratings of each respondent were used to calculate an initial set of attribute level utilities. Next, these initial utilities were refined based on responses to the attribute importance questions, so that the range of utilities within each attribute was proportional to the stated importance. Finally, based on the responses to the paired comparison questions, ordinary least squares regression was used to calculate the final set of utilities for the attribute levels. ${ }^{35}$ The utilities were summed for different treatment profiles (based on the respective combinations of attribute levels) to determine which treatment would be preferred.

Relative importance, expressed as a percentage of each of the attributes in influencing treatment decisions, was calculated for each participant by dividing the range of each attribute (utility of highest level-utility of lowest level) by the sum of ranges of all attributes, and multiplying it by 100. The utilities also were incorporated into regression models that added random variability at both the attribute and product levels. Approximately 100,000 sampling iterations were then performed, yielding predictions about the percentages of patients who would choose a specific treatment profile over the others offered. Given the utility estimates generated for each attribute level, sensitivity analyses were also conducted to estimate the percentages of patients likely to choose each treatment over the others, given a range of hypothetic simulation scenarios.

\section{Results}

A total of 171 patients completed the survey. Of these, $161(94 \%)$ were included in the final analytic dataset. Ten participants were excluded due to two or more illogical answers for the desirability of attributes section (eg, choosing a $1 \%$ chance of heart attack/stroke as more desirable than a $0 \%$ chance). The study population had a mean age of 61 years (standard deviation [SD] 13, range 26-89), 79\% were Caucasian, 44\% were college educated, and 55\% were males. The mean time $( \pm \mathrm{SD})$ since DR diagnosis was $8.7 \pm 8.5$ years. Thirty-one percent had diabetic macular edema, 25\% had proliferative diabetic retinopathy, $26 \%$ had both, and $18 \%$ had neither. Forty-nine percent $(n=79)$ were treated with laser only, 3\% $(n=5)$ with injection (either steroid and/or anti-VEGF) only, $22 \%(\mathrm{n}=36)$ with both laser and injection, and $25 \%(\mathrm{n}=41)$ were treatment-naive. Overall, 57\% and $37 \%$ had scotomas (blurry or blank patches) in their central and side vision, respectively. Fifty-three percent had cataracts, and 37\% had undergone cataract surgery.

The responses to the first survey section consistently showed higher ratings for the more favorable attribute levels and lower ratings for the less favorable levels. For the administration mode attribute, the mean desirability ratings overall for focal laser, injection, and panretinal laser modalities were 4.63, 3.69, and 3.42, respectively (range 1-7, with higher more favorable). Within subgroups, the mean desirability rating for injection was 3.17 among treatment-naïve patients, and was 4.97 among those who have experienced both laser and injection.

Table 2 reports the relative importance estimates for each attribute based on their respective utilities. They reflect the extent to which the difference in importance between the best and worst levels of each attribute drives the decision to choose a DR treatment. Among all 11 attributes, those directly related to visual functioning were valued most highly by patients. Specifically, these were "chance of 
Table 2 Relative importance of attributes in influencing patient preferences

\begin{tabular}{|c|c|c|c|}
\hline Attribute & Most favorable level & Least favorable level & $\begin{array}{l}\text { Relative importance } \\
(\% \pm \text { SEM })^{\mathrm{a}}\end{array}$ \\
\hline $\begin{array}{l}\text { Chance of cataract } \\
\text { formation }\end{array}$ & $0 \%$ & $54 \%$ & $12.8 \pm 0.03$ \\
\hline $\begin{array}{l}\text { Chance of improving } \\
\text { vision }\end{array}$ & $55 \%$ & $15 \%$ & $12.3 \pm 0.06$ \\
\hline $\begin{array}{l}\text { Chance of blurry/blank } \\
\text { patches, side }\end{array}$ & $0 \%$ & $47 \%$ & $11.5 \pm 0.03$ \\
\hline $\begin{array}{l}\text { Chance of blurry/blank } \\
\text { patches, central }\end{array}$ & $0 \%$ & $20 \%$ & $10.9 \pm 0.02$ \\
\hline $\begin{array}{l}\text { Benefit observed from } \\
\text { subsequent treatments }\end{array}$ & $\begin{array}{l}\text { After treatment wears off, same } \\
\text { benefit is observed with } \\
\text { each subsequent treatment }\end{array}$ & $\begin{array}{l}\text { After treatment wears off, } \\
\text { treatment benefit decreases } \\
\text { with each subsequent treatment }\end{array}$ & $9.6 \pm 0.03$ \\
\hline $\begin{array}{l}\text { Chance of needing daily } \\
\text { drops for glaucoma }\end{array}$ & $0 \%$ & $50 \%$ & $9.6 \pm 0.03$ \\
\hline Chance of cardiovascular event & $0 \%$ & $3 \%$ & $9.3 \pm 0.03$ \\
\hline $\begin{array}{l}\text { Chance of needing } \\
\text { surgery for glaucoma }\end{array}$ & $0 \%$ & $5 \%$ & $8.6 \pm 0.03$ \\
\hline Number of physician visits & I visit & 9 visits & $6.1 \pm 0.03$ \\
\hline Treatment-related pain & $\begin{array}{l}\text { Mild pain at the time } \\
\text { of treatment }\end{array}$ & $\begin{array}{l}\text { Moderate pain at the time of } \\
\text { treatment, and some pain after } \\
\text { treatment lasting for a day }\end{array}$ & $5.5 \pm 0.03$ \\
\hline Mode of administration & $\begin{array}{l}\text { Laser procedure, in which } \\
40-60 \text { spots are placed on } \\
\text { a small area of the central retina }\end{array}$ & $\begin{array}{l}\text { Laser procedure, in which approximately } \\
500 \text { spots are placed across the retina }\end{array}$ & $3.8 \pm 0.03$ \\
\hline
\end{tabular}

Note: ${ }^{\text {Ratio data }}$ ( $10 \%$ is twice as important than $5 \%$ ).

Abbreviation: SEM standard error of the mean.

improving central vision" (efficacy) and the chance of side effects that would contribute to further visual loss, such as cataract formation. Thus changes in these attributes would make the most difference in the perceived utility of a DR treatment. The visual functioning attributes (ie, chance of cataract formation, improving vision, peripheral or paracentral scotomas) each accounted for $10.9 \%$ to $12.8 \%$ of the total relative importance. The attributes that least impacted preferences were treatment-related pain, number of office visits, and mode of administration. Patients were willing to endure a higher frequency of office visits or injection or greater treatment-related pain in exchange for greater efficacy, increased long-term benefit, and reduced risk of visual side effects (cataracts or scotomas). The relative importance estimates did not change substantially within subgroups based on past treatment experience, age, or previous cataract experience, and thus have not been tabulated.

Table 3 reports the estimated percentages of patients preferring each DR treatment given the utilities for the base case attribute levels. In the overall population, an estimated $52 \%$ of patients would prefer anti-VEGF over the other treatments. Steroid therapy would be the second most preferred $(20 \%)$, followed by focal laser $(17 \%)$ and panretinal laser $(11 \%)$. The estimated percentages did not differ substantially across subpopulations based on past treatment experience. Table 4 reports the percentages preferring each treatment profile stratified by type of retinopathy. The estimates are consistent with those observed for the subgroups categorized by treatment experience (from most to least preferred, anti-VEGF, steroid, focal laser, panretinal laser),

Table 3 Estimated percentages of patients preferring each diabetic retinopathy treatment given utilities of base case attributes

\begin{tabular}{|c|c|c|c|c|c|}
\hline $\begin{array}{l}\text { DR } \\
\text { treatment }\end{array}$ & $\begin{array}{l}\text { Overall } \\
(n=I 6 I) \\
\%(S E M)\end{array}$ & $\begin{array}{l}\text { Treatment- } \\
\text { naïve }(n=4 I) \\
\%(S E M)\end{array}$ & $\begin{array}{l}\text { Laser experience } \\
(n=79) \\
\%(\text { SEM) }\end{array}$ & $\begin{array}{l}\text { Injection } \\
\text { experience }(n=5) \\
\%(\text { SEM) }\end{array}$ & $\begin{array}{l}\text { Experience with both } \\
\text { therapies }(n=36) \\
\%(\text { SEM) }\end{array}$ \\
\hline Anti-VEGF & $52 \%(1.7)$ & $49 \%(3.8)$ & $51 \%(2.2)$ & $56 \%(8.5)$ & $57 \%(3.3)$ \\
\hline Steroid & $20 \%(1.2)$ & $21 \%(2.4)$ & $18 \%(1.4)$ & $15 \%(2.8)$ & $26 \%(3.0)$ \\
\hline Focal laser & $17 \%(I . I)$ & $19 \%(2.4)$ & $19 \%(1.7)$ & $16 \%(7.8)$ & $10 \%(1.3)$ \\
\hline Panretinal laser & II\% (0.8) & II\% (I.6) & $12 \%(1.2)$ & $13 \%(1.9)$ & $7 \%(1.4)$ \\
\hline
\end{tabular}

Abbreviations: DR, diabetic retinopathy; VEGR, vascular endothelial growth factor; SEM, standard error of the mean. 
Table 4 Estimated percentages of patients preferring each diabetic retinopathy treatment given utilities of base case attributes by diabetic macular edema/proliferative diabetic retinopathy status

\begin{tabular}{lllll}
\hline $\begin{array}{l}\text { DR } \\
\text { treatment }\end{array}$ & $\begin{array}{l}\text { Neither DME nor PDR }(\mathbf{n}=\mathbf{2 9}) \\
\%(\text { SEM) }\end{array}$ & $\begin{array}{l}\text { DME only }(\mathbf{n}=\mathbf{5 0}) \\
\%(\mathrm{SEM})\end{array}$ & $\begin{array}{l}\text { PDR only }(\mathbf{n}=40) \\
\%(S E M)\end{array}$ & $\begin{array}{l}\text { Both DME and PDR }(\mathbf{n}=42) \\
\%(\text { SEM) }\end{array}$ \\
\hline Anti-VEGF & $51 \%(3.6)$ & $56 \%(2.8)$ & $46 \%(3.7)$ & $54 \%(3.1)$ \\
Steroid & $21 \%(2.4)$ & $14 \%(1.3)$ & $27 \%(2.9)$ & $21 \%(1.9)$ \\
Focal laser & $17 \%(2.9)$ & $19 \%(2.1)$ & $17 \%(2.5)$ & $15 \%(1.8)$ \\
Panretinal laser & $11 \%(1.7)$ & $12 \%(1.3)$ & $10 \%(1.8)$ & $11 \%(1.6)$ \\
\hline
\end{tabular}

Abbreviations: VEGF, vascular endothelial growth factor; DME, diabetic macular edema; DR, diabetic retinopathy; PDR, proliferative diabetic retinopathy; SEM, standard error of the mean.

with the exception that more patients with diabetic macular edema preferred the focal laser over steroid treatment (19\% versus $14 \%$, respectively).

Table 5 reports the percentages preferring each DR treatment, given improvements in base case attribute levels for steroid, focal laser, and panretinal laser treatment. A series of stepwise analyses were performed such that improvements to individual attributes were implemented until each of antiVEGF's comparators was preferred over anti-VEGF. Steroid therapy was preferred over anti-VEGF after improvements were made to the "chance of cataract formation" and "benefit with subsequent treatment". Focal laser was preferred over anti-VEGF when improvements were made to risk of central scotomas and "benefit with subsequent treatment", and panretinal laser required improvements in "benefit with subsequent treatment" and risk of peripheral scotomas to be preferred over anti-VEGF.

Finally, a stepwise analysis of anti-VEGF involved modifications to make the attributes less favorable. Worsening the attributes "pain" (from "mild" to "moderate") and "chance of improving central vision" (from 30\% to 15\%) resulted in a slight shift in preference to steroid treatment.
Specifically, with these changes, $32 \%, 31 \%, 22 \%$, and $16 \%$ preferred steroid, anti-VEGF, focal laser, and panretinal laser therapies, respectively.

\section{Discussion}

To our knowledge, this study was the first to assess patient treatment preferences in DR. The DR treatment attributes valued most highly by patients were those that are directly related to visual functioning, including efficacy of the treatment and chance of adverse events that could contribute to further visual loss. Least important were those attributes that did not directly affect vision, such as treatment-related pain and mode of administration. These results emphasize the importance that patients place on visual functioning and the impact it has on their quality of life. For example, some patients may not be willing to accept a treatment with a possibility of improved efficacy if it is coupled with a greater chance of adverse events that may ultimately negatively affect vision.

The findings of this study were consistent with those of Bhargava et al who performed a conjoint study to assess attributes associated with glaucoma treatment in that

Table 5 Sensitivity analyses: Percentages preferring each diabetic retinopathy treatment given improvements in base case attribute levels*

\begin{tabular}{|c|c|c|c|c|}
\hline Attribute improvements & $\begin{array}{l}\text { Preferring } \\
\text { anti-VEGF (\%) }\end{array}$ & $\begin{array}{l}\text { Preferring } \\
\text { steroid (\%) }\end{array}$ & $\begin{array}{l}\text { Preferring } \\
\text { focal laser (\%) }\end{array}$ & $\begin{array}{l}\text { Preferring } \\
\text { panretinal laser (\%) }\end{array}$ \\
\hline \multicolumn{5}{|l|}{ Improvements to steroid treatment: } \\
\hline $\begin{array}{l}\text { - Cataracts ( } 40 \% \text { to } 0 \%) \\
\text { - Benefit (benefit decreases to same } \\
\text { benefit with subsequent treatment) }\end{array}$ & $25 \%$ & $59 \%$ & $9 \%$ & $7 \%$ \\
\hline \multicolumn{5}{|l|}{ Improvements to focal laser: } \\
\hline $\begin{array}{l}\text { - Blurry/blank patches, central ( } 20 \% \text { to } 0 \%) \\
\text { - Benefit (benefit decreases to same } \\
\text { benefit with subsequent treatment) }\end{array}$ & $31 \%$ & $12 \%$ & $51 \%$ & $6 \%$ \\
\hline \multicolumn{5}{|l|}{ Improvements to panretinal laser: } \\
\hline $\begin{array}{l}\text { - Benefit (benefit decreases to same } \\
\text { benefit with subsequent treatment) } \\
\text { - Blurry/blank patches, peripheral (33\% to } 0 \% \text { ) }\end{array}$ & $35 \%$ & $14 \%$ & $10 \%$ & $41 \%$ \\
\hline
\end{tabular}

Note: $*$ Table presents all attributes that are needed to improve in order for the respective treatment to be more preferred than anti-VEGF.

Abbreviation: VEGF, vascular endothelial growth factor. 
the attributes substantially affecting visual functioning (side effects) ranked highest in relative importance and those related to treatment methods ranked lowest. ${ }^{26}$ Specifically, Bhargava's findings showed that the most important treatment-related attributes for glaucoma were the risk of moderate visual loss (ie, the ability to continue to drive) and risk of long-term blindness. Least important included chance of surgical intervention and the use of topical medication. In our study of Canadian diabetic patients, the chances of cataract formation, improving vision, and pericentral or peripheral scotomas made the most difference in the perceived utility of a DR treatment relative to other treatment attributes. In addition, our findings on importance were consistent with conclusions from conjoint studies in other medical disciplines. In a recent study of disease-modifying antirheumatic preferences, for example, the tradeoffs made by patients with rheumatoid arthritis suggested that adverse events (eg, nausea, diarrhea) from a therapy were a significant driver of overall preference. ${ }^{34}$

The risk of cataract formation was a key driver in selecting a DR treatment, and the findings did not vary between those with versus those without cataract experience, or between those with versus those without cataract surgery experience. This finding indicates that, even though cataract surgery is a relatively safe, quick, and predominantly painless procedure, patients still are willing to give up other favorable treatment attributes to avoid the risk of cataract development and surgery.

Our study co mpared the treatment preferences of patients who had never undergone DR therapy with those who had experienced injection (steroid or anti-VEGF), laser (focal or panretinal), or both. Preferences did not vary substantially between subgroups, suggesting that decisions are driven by the same factors (ie, those that relate directly to vision improvement or impairment) for all types of DR patients, regardless of treatment history. Even in patients who had experienced both laser and injection treatments, the preference for anti-VEGF was strong, despite the disadvantage of anti-VEGF requiring frequent injections.

Our study had limitations. First, the treatment attribute descriptions were limited to what is expected over a one-year treatment period. Longer-term studies have shown that efficacy, for example, is better for the focal laser versus steroid therapy over a 2-year period; thus, if we were to expand our time horizon, the results may differ significantly. Second, given that focal and panretinal lasers are the mainstay of DR treatment, and anti-VEGF and steroid are offlabel therapies, our sample included only five patients who had experience with injection but not laser therapy. In addition, our study was initiated before it was demonstrated in the literature that anti-VEGF carried a significant risk of endophthalmitis (intraocular inflammation, which can result in severe vision loss), ${ }^{36,37}$ and so this risk was not included as an attribute. It is possible that inclusion of endophthalmitis would have resulted in a weaker preference for anti-VEGF, although the sensitivity analyses showed that multiple modifications to the base case would be necessary to shift preferences away from this therapy.

Further limitations are that the participants in our sample did not represent the full range of patients with DR; the majority were well educated (with at least some college education), and their vision loss was not so significant that they were unable to navigate through the survey. It is possible that patients with other sociodemographic and clinical characteristics, particularly related to severity of visual impairment, would express preferences different from those expressed by our sample. In addition, a subset of our sample had never undergone laser or injection-based therapy, so we cannot be certain whether preferences for treatment of these patients would change after a treatment experience. Our analysis suggests they would not. Further, all of the patients in our study were from Canada, where the socialized health care system prevents cost of treatment from being a driver or barrier to selecting treatment. In other industrialized nations, such as the US, treatment-related costs could present as an important factor determining patient preferences. Therefore, while our study has yielded important findings with implications for the medical community, future research is necessary to evaluate the generalizability of our conclusions.

\section{Conclusion}

In conclusion, this survey evaluated the tradeoffs that patients are willing to make among DR treatment attributes and predicted treatment preferences under different medication scenarios. As may be expected, the most favored attributes were those associated with improving vision or preventing visual loss. Given that diabetes is increasing in prevalence globally, the volume of ophthalmic patients will also increase and require increased patient-physician partnership for better long-term DR management. The findings from this research may be useful in incorporating patients' views into medical decision-making processes, patient education, cost resource allocations, and drug development. A better understanding of a patient's preferences may help 
to improve patient satisfaction and compliance with chronic DR management.

\section{Acknowledgments}

The authors thank the following individuals for assisting with data collection: Dr Hugh Tildesley, Hamish Tildesley, and Stephanie Wise at the University of Ottawa Eye Institute in Ottawa, Ontario; Dr John Gonder and Marilyn Strauss at the Ivey Eye Institute in London, Ontario; and Dr Michael Potter and Nicole Peterson at UBC Eye Care Centre in Vancouver, British Columbia.

\section{Disclosure}

This study was carried out by Oxford Outcomes Inc., with funding provided by Pfizer US Inc. AP, BW, and AB are employees of Pfizer Inc. KB and JG are employees of Oxford Outcomes. TC has served on advisory boards for and received honoraria and travel and accommodation payments from Pfizer, Alimera, Allergan, Genentech, Regeneron, and Thrombogenics. JG has served on advisory boards and received honoraria and payments from Pfizer and Alcon.

\section{References}

1. Brown AB, Meltzer DO, Chin MH, Huang ES. Perceptions of quality-of-life effects of treatments for diabetes mellitus in vulnerable and nonvulnerable older patients. J Am Geriatr Soc. 2008;56: 1183-1190.

2. Sloan FA, Padròn NA, Platt AC. Preferences, beliefs, and selfmanagement of diabetes. Health Serv Res. 2009;44:1068-1087.

3. McGlynn E, Asch S, Adams J, et al. The quality of health care delivered to adults in the United States. N Engl J Med. 2003;348:2635-2645.

4. Anderson RT, Skovlund SE, Marrero D, et al. Development and validation of the Insulin Treatment Satisfaction Questionnaire. Clin Ther. 2004;26:565-578.

5. Lingvay I, Legendre JL, Kaloyanova PF, Zhang S, Adams-Huet B, Raskin P. Insulin-based versus triple oral therapy for newly diagnosed Type 2 diabetes: Which is better? Diabetes Care. 2009;32:1789-1795.

6. Matza LS, Boye KS, Yurgin N, et al. Utilities and disutilities for type 2 diabetes treatment-related attributes. Qual Life Res. 2007;16:1251-1265.

7. Huang ES, Shook M, Jin L, Chin MH, Meltzer DO. The impact of patient preferences on the cost-effectiveness of intensive glucose control in older patients with new-onset diabetes. Diabetes Care. 2006;29: 259-264.

8. Hutchinson A, McIntosh A, Peters J, et al. Clinical Guidelines and Evidence Review for Type 2 Diabetes. Diabetic retinopathy: Early management and screening. Sheffield, UK: ScHARR, University of Sheffield; 2001.

9. Lee J, Bailey G. Diabetic retinopathy. Access Media Group LLC, c2000-10 [Updated 2007 June]. Available from: http://www. allaboutvision.com/conditions/diabetic.htm. Accessed 2008 Sep 16.

10. Klein R, Klein BEK, Moss SE, Cruickshanks KJ. The Wisconsin epidemiologic-study of diabetic retinopathy: The long-term incidence of macular edema. Ophthalmology. 1995;102:7-16.

11. Saaddine JB, Honeycutt AA, Narayan KM, et al. Projection of diabetic retinopathy and other major eye diseases among people with diabetes mellitus: United States, 2005-2050. Arch Ophthalmol. 2008;126: 1740-1747.
12. Sammartin C, Gilmore J. Statistics Canada. Diabetes care in Canada: Results from selected provinces and territory, 2005. [Updated 2006 Oct 20] Available from: http://www.statcan.gc.ca/pub/82-621-x/2006002/4053724-eng. htm\#source. Accessed 2008 Sep 16.

13. Early Treatment Diabetic Retinopathy Study (ETDRS) research group. Photocoagulation for diabetic macular edema. Early Treatment Diabetic Retinopathy Study report number 1. Arch Ophthalmol. 1985;103: 1796-1806.

14. Ferris FL III. How effective are treatments for diabetic retinopathy? JAMA. 1993;269:1290-1291.

15. Han Y, Schneck ME, Bearse MA, et al. Formulation and evaluation of a predictive model to identify the sites of future diabetic retinopathy. Invest Ophthalmol Vis Sci. 2004;45:4106-4112.

16. Churchill AJ, Carter JG, Ramsden C, et al. VEGF polymorphisms are associated with severity of diabetic retinopathy. Invest Ophthalmol Vis Sci. 2008;49:3611-3616.

17. Diabetic Retinopathy Study Research Group. Preliminary report on effects of photocoagulation therapy. Am J Ophthalmol. 1976;81:383-396.

18. Chalam KV, Lin S, Mostafa S. Management of diabetic retinopathy in the twenty-first century. Northeast Florida Medicine. 2005;569(2): $8-15$.

19. Dowler J. Laser management of diabetic retinopathy. Journal of the Royal Society of Medicine. 2003;96:277-279. Available from: http://www.pubmedcentral.nih.gov/articlerender.fcgi?artid=539507. Accessed 2010 Aug 28.

20. Early Treatment of Diabetic Retinopathy Study Group. Early photocoagulation for diabetic retinopathy. ETDRS report number 9. Ophthalmology. 1991;98:766-785.

21. Wirostko B, Wong T, Simo R. Vascular endothelial growth factor and diabetic complications. Prog Retin Eye Res. 2008;27:608-621.

22. Brunner S, Schernthaner G, Satler M, et al. Correlation of different circulating endothelial progenitor cells to stages of diabetic retinopathy - first in vivo data. Invest Ophthalmol Vis Sci. 2009;50:392-398.

23. Green PE, Srinivasan V. Conjoint analysis in marketing: New developments with implications for research and practice. Journal of Marketing. 1990;54:3-517.

24. Ryan M, Farrar $\mathrm{S}$. Using conjoint analysis to elicit preferences for health care. $B M J .2000 ; 320: 1530-1533$.

25. Beusterien KM, Dziekan K, Flood E, et al. Understanding patient preferences for HIV medications using adaptive conjoint analysis: Feasibility assessment. Value Health. 2005;8:453-461.

26. Bhargava JS, Patel B, Foss AJ, et al. Views of glaucoma patients on aspects of their treatment: An assessment of patient preference by conjoint analysis. Invest Ophthalmol Vis Sci. 2006;47:2885-2888.

27. Blankenship GW. Diabetic macular edema and Argon laser photocoagulation: A prospective randomized study. Ophthalmology. 1979;86: 69-75.

28. Fong DS, Girach A, Boney A. Visual side effects of successful scatter laser photocoagulation surgery for proliferative diabetic retinopathy: A literature review. Retina. 2007;27:816-824.

29. Margolis R, Singh R, Bhatnagar P, Kaiser P. Intravitreal triamcinolone as adjunctive treatment to laser panretinal photocoagulation for concomitant proliferative diabetic retinopathy and clinically significant macular oedema. Acta Ophthalmol Scand. 2008;1:105-110.

30. Sutter F, Simpson J, Gillies M. Intravitreal triamcinolone for diabetic macular edema that persists after laser treatment: Three-month efficacy and safety results of a prospective, randomized, double-masked, placebocontrolled clinical trial. Ophthalmology. 2004;111:2044-2049.

31. Mohamed Q, Gillies M, Wong T. Management of diabetic retinopathy: A systematic review. JAMA. 2007;298:902-916.

32. Seiberth V, Alexandridis E. Function of the diabetic retina after panretinal argon laser photocoagulation. Influence of the intensity of the coagulation spots. Ophthalmologica. 1991;202:10-17.

33. Seiberth V, Schatanek S, Alexandridis E. Panretinal photocoagulation in diabetic retinopathy: Argon versus dye laser coagulation. Graefes Arch Clin Exp Ophthalmol. 1993,231:318-322. 
34. Fraenkel L, Bogardus ST, Concato J, Felson DT, Wittink DR. Patient preferences for treatment of rheumatoid arthritis. Ann Rheum Dis. 2004; 63:1372-1378.

35. ACA Technical Paper. Sawtooth Software, Sequim, WA. Available from: http://www.sawtoothsoftware.com. Accessed 2008 Nov 13.
36. Klein KS, Walsh MK, Hassan TS, et al. Endophthalmitis after anti-VEGF injections. Ophthalmology. 2009;116:1225.e1.

37. Artunay O, Yuzbasioglu E, Rasier R, Sengül A, Bahcecioglu H. Incidence and management of acute endophthalmitis after intraviteral bevacizumab (Avastin) injection. Eye. 2009;23:2187-2193.

\section{Publish your work in this journal}

Patient Preference and Adherence is an international, peer-reviewed, open access journal focusing on the growing importance of patient preference and adherence throughout the therapeutic continuum. Patient satisfaction, acceptability, quality of life, compliance, persistence and their role in developing new therapeutic modalities and compounds to optimize clinical outcomes for existing disease states are major areas of interest. This journal has been accepted for indexing on PubMed Central. The manuscript management system is completely online and includes a very quick and fair peer-review system. Visit http://www.dovepress.com/ testimonials.php to read real quotes from published authors.

\footnotetext{
Submit your manuscript here: http://www.dovepress.com/patient-preference-and-adherence-journal
} 